\title{
Effect of Seaweed Powder on the Quality of the Pineapple-Chili Sauce
}

\author{
Mansoor Abdul Hamid ${ }^{1}$, Tan Pei Shan ${ }^{2}$, Mazarina Devi ${ }^{3}$, Wolyna Pindi ${ }^{4}$, Jahurul \\ Haque Akanda ${ }^{5}$, Hasmadi Mamat ${ }^{6}$, Fan Hui Yin ${ }^{7}$ \\ ${ }^{1,2,4,5,6,7}$ Faculty of Food Science \& Nutrition, Universiti Malaysia Sabah, Jalan UMS, 88400 Kota Kinabalu, Sabah. \\ Malaysia. \\ ${ }^{3}$ Prodi Pendidikan, Tata Boga, Fakultas Teknik, Universitas Negeri Malang, Jalan Semarang 5, Malang, 65145 \\ Indonesia. \\ *Corresponding author: chot@ums.edu.my
}

\begin{abstract}
.
This study was conducted to produce pineapple-chili sauce mixed with seaweed (Kappaphycus alvarezii) based on the best formulation, to determine nutritional composition of the control and the best formulation and to determine the effect on quality of this product. A total of 3 formulations had been developed using different composition of seaweed powder at $2.0 \%, 2.5 \%, 3.0 \%$ and were undergo sensory evaluation and physicochemical analysis to choose the best formulation. The selected and control samples were then analysed for proximate values. The increasing in seaweed powder composition influenced significantly $(\mathrm{p}<0.05)$ the aroma, viscosity, aftertaste and overall acceptability of the sauces. In the physicochemical analysis, increasing in seaweed powder percentage was significantly $(\mathrm{p}<0.05)$ influenced positively in the viscosity, syneresis and water activity while it did not affect $(\mathrm{p}>0.05)$ the total soluble solids, total acidity and $\mathrm{pH}$. The results of proximate analysis shown the composition of the best formulation was $72.54 \%$ moisture content, $23.44 \%$ carbohydrate, $2.70 \%$ ash, $0.81 \%$ crude fibre, $0.37 \%$ crude protein and $0.14 \%$ rude fat showed significantly higher $(\mathrm{p}<0.05)$ in ash, crude protein, and crude fibre compared to control.
\end{abstract}

Keywords: Kappaphycus alvarezii, seaweed powder, sauce, sensory evaluation, physicochemical property

\section{INTRODUCTION}

Nowadays sauces become popular convenient food product among the population due to the changes in the lifestyles and the changes in the eating habits. In Malaysia, consumption of sauces has shown an increase of 75,567.5 MT in 2010 to $84,565.2$ MT in 2015 and is believed to be increased further to $91,028.7 \mathrm{MT}$ in 2020 [1]. In the local market, fruit sauces had become increasingly popular as they provide various interesting natural flavour and taste profiles which meet the consumer demand. Besides that, production of fruit sauces can be defined as a way to preserve the fruits, to extend their shelf life and to avoid the wastage of fruits. However, the market for sauces had become more limited as the food producers and manufacturers produce same types of sauce and they are forced to compete as well as cannot meet the demand of consumer on trying new flavour [2].

Pineapple is the main choice in the processing of fruit sauces because of its natural colour, strong flavour, high sugar content, and natural acidity which suitable be eaten as dessert $[3,4]$. Pineapple is also rich in nutrients that can provide health benefits, such as vitamins, mineral, phenolic and fibre. In addition, pineapple is a tropical fruit which can easily found in the local market throughout the year. Thus, it had been commercially processed into products with additional values such as sauces, jam, juice, candy and vinegar [5].

Seaweed is macroalgae with its economic value are increasing in the world market now. Recently, the used of seaweed is becoming popular in the food industry for the production of nutritious and functional food due to it rich of polysaccharides, mineral, fiber, protein and omega-3 fatty acid [6.7]. Furthermore, seaweed is the source of hydrocolloids which usually can be used as a thickening agent, gelling agent, emulsifier, and stabilizer in various food product processing such as sauces, ice cream and soup [8].

In Malaysia, Kappaphycus alvarezii is the most common type of red seaweed which had been cultivated largely in the farms around Sabah. It became high demand because it is an important source of kappa-carrageenan for industrial applications, either used in fresh or in powder form. It also is considered as a sustainable food source and a low-cost raw material [9]. However, the use of seaweed is still limited in the local food industries. In local usage, seaweed mainly used in the production of salad, soup and pudding [10]. The fishy smell of seaweed also makes it become unacceptable and less consumable among consumer [11]. In order to make seaweed more commercialize and diversify the use of seaweed, as well as to increase the sauce variety in the market, seaweed (Kappaphycus 
alvarezii) powder is used as a thickening agent in the production of pineapple-chili sauce.

The study was conducted to determine the best formulation of pineapple-chili sauce mixed with seaweed through sensory evaluation and physicochemical analysis, to determine the nutrient composition of the control and the best formulation of pineapple-chili sauce mixed with seaweed and to study the effect of seaweed powder on the quality of the sauce.

\section{MATERIALS AND METHODS}

\subsection{Materials}

Pineapple, seaweed Kappaphycus alvarezii, chili and garlic were purchase from the wet market, Kota Kinabalu. Other raw materials to produce pineapple-chili sauce such as sugar, modified corn starch, xanthan gum, citric acid and sodium benzoate were purchase from Bake with Me, Jalan Lintas, Kota Kinabalu.

\subsection{Preparation of Seaweed Powder}

The seaweed was washed with water, dried in a drying cabinet (Thermoline TD-78T-SD, Australia) at $50^{\circ} \mathrm{C}$ for 48 hours and was ground using a grinder (Panasonic, Japan). Them, it was sifted using sieve shaker (Minor $1760-07, \mathrm{UK})$ to make a fine powder $(0.25 \mathrm{~mm})$.

\subsection{Preparation of Sauce}

The sauces were prepared according to the formulation by [12] with modification by added seaweed powder in a range of $2.0-3.0 \%$. The pineapple was cleaned, peeled, sliced and blended (Panasonic, Japan) to make a puree. Chili was washed and unseeded, garlic skin was removed and they were blended together. Later, pineapple puree, chili and garlic were mixed inside a cooking pot, heated and stirred regularly. Sugar and salt were put in the pot and the mixture was boiled. Seaweed powder was added into the mixture and was stirred until dissolved. After that, citric acid and sodium benzoate were added into the mixture and the mixture was boiled. The sauce was lifted and was filled into a sterilized bottle while still hot and was closed immediately.

\subsection{Sensory Evaluation}

The hedonic test was conducted to determine the best formulation of the sauce among F1, F2 and F3. A total of 40 panellists were selected randomly from the Faculty of Food Science and Nutrition, University Malaysia Sabah (FSMP, UMS). The hedonic test has used a seven-point Likert scale to assess the sensory attributes (colour, taste, aroma, viscosity, aftertaste and overall acceptance) of the given sauce samples. A hedonic scale score 1 represents dislike extremely while score 7 represents like extremely. The sauce samples have been served with cucumbers and warm water was provided to rinse the mouth.

\subsection{Physicochemical Analysis}

\subsubsection{Syneresis test}

Syneresis test was conducted using the centrifugation method with centrifuge machine (Thermo Scientific, Sorvaii Biofuge Prime R) [13]. A sample of $10.00 \pm 0.01 \mathrm{~g}$ was centrifuged for 30 minutes at $3000 \mathrm{~g}$ and the percentage was calculated based on equation 1 .

$\begin{array}{llll}\text { Syneresis }(\%)= & \frac{\mathrm{a}}{\mathrm{b}} & \mathrm{x} & 100\end{array}$

[1]

Where,

$\mathrm{a}=$ weight of water separated from the sample $(\mathrm{g})$

$\mathrm{b}=$ total weight of the sample prior to centrifugation $(\mathrm{g})$

\subsubsection{Water activity}

The water activity of the sample was measured using a water activity meter (Rotronic HygroLab) and was set at $105^{\circ} \mathrm{C}$ [13]. Water activity was shown as equilibrium relative humidity $(\mathrm{ERH})$.

\subsubsection{Viscosity}

The viscosity of the sample was determined using the Brookfield viscometer DV-l type $1+$ Pro (AOAC, 2000). Sample of $250.00 \pm 0.01 \mathrm{~g}$ was placed into a $250 \mathrm{ml}$ beaker before the viscometer fixed with spindle 5 and rotation set at $30 \mathrm{rpm}$.

\subsection{4 $\mathrm{pH}$ value}

The $\mathrm{pH}$ of the sample was measured using $\mathrm{pH}$ meter with type BP 3100, UI TransInstrument [14] where $100 \pm$ $0.01 \mathrm{~g}$ sample was place in the beaker, the $\mathrm{pH}$ probe was then penetrated into the sample and the stable reading was indicated.

\subsubsection{Total soluble solids}

Determination of total soluble solids is carried out using a hand refractometer ATAGO type $(\mathrm{N}-2 \mathrm{E})$ which has a range between $28^{\circ}-62^{\circ}$ Brix [14].

\subsubsection{Total acidity}

Determination of total acidity was conducted using the titration method [15]. Total acidity of the sample is regarded as a percent of citric acid and it was calculated based on the equation 2 . Three replicates were performed for each sample.

\begin{tabular}{|c|c|c|c|c|c|}
\hline Total & Acidity & $(\%)$ & $=$ & $\frac{\mathrm{Vx} N \mathrm{NX}}{\mathrm{S}}$ & $X$ \\
\hline
\end{tabular}

Where,

$\mathrm{V}=$ average volume of $\mathrm{NaOH}$ required to neutralize the acidity of the sample

$\mathrm{N}=$ normality of $\mathrm{NaOH}$

$\mathrm{F}=$ factor milliequivalent citric acid (0.064)

$\mathrm{S}=$ weight of a sample 


\subsection{Proximate Analysis}

Control and best formulation were choosing to undergo proximate analysis which included the moisture content, ash, crude protein, crude fat, crude fibre and total carbohydrates were determined according to [15]. Moisture was analysed in an oven at $105^{\circ} \mathrm{C}$ for 24 hours. Ash was analysed by burning the sample in a furnace at $550^{\circ} \mathrm{C}$ overnight. Kjedahl method was used to determine protein content while the Soxhlet method was used to determine fat content. Crude fiber was determined using the gravimetric method. Carbohydrates were calculated by the difference method which is shown in equation 3 .

\section{Carbohydrate Content $(\%)=100 \%-(\mathrm{a}+\mathrm{b}+\mathrm{c}+\mathrm{d}+\mathrm{e})$} [3]

Where,

$$
\begin{aligned}
& \mathrm{a}=\text { water content }(\%) \\
& \mathrm{b}=\operatorname{ash}(\%) \\
& \mathrm{c}=\text { fat }(\%) \\
& \mathrm{d}=\text { protein }(5) \\
& \mathrm{e}=\text { crude fiber }(\%)
\end{aligned}
$$

\subsection{Statistical Analysis}

All analysis done in triplicate and data were expressed as means \pm standard deviations. Data were analysed by using IBM SPSS Statistics Version 22.0 and the significant difference was considered at the level of $p<0.05$. A hedonic test was analysed by the Friedman test followed by Wilcoxon Signed Ranks Test. Independent Group t-test was used to analyse the results of the proximate analysis. One-way ANOVA and Tukey test were used to analyse the significant differences between the samples of sauce tested.

\section{RESULTS AND DISCUSSION}

\subsection{Sensory Evaluation And Physicochemical Properties Of Pineapple Chili Sauce Mixed with Seaweed Powder}

Sensory evaluation of these three formulations showed that the percentage of seaweed powder added affected several attributes measured such as aroma, viscosity, aftertaste and overall acceptance. Additional of seaweed powder at 3.0\% gave significantly $(\mathrm{p}<0.05)$ lower aroma score due to fishy smell of the product can be detected by the panels. The viscosity of sample added with $2.5 \%$ seaweed powder was most accepted $(p<0.05)$ by the panels due to its consistent and sticky properly on the carrier. Aftertaste of $3.0 \%$ seaweed powder added give unpleasant flavour due to the fishy taste of the sample. Seaweed has a neutral taste, thus increasing the composition of seaweed powder in the samples would not affect the taste such as sweetness and sourness [16]. Overall acceptability of panel chosen F2 was the best and the detail was shown in table 1 .

Table 1: The hedonic scale sensory evaluation for pineapple chili sauce mixed with seaweed powder

\begin{tabular}{cccc}
\hline Attributes & \multicolumn{3}{c}{ Formulation } \\
\cline { 2 - 4 } & F1 & F2 & F3 \\
\cline { 2 - 4 } Colour & $5.58 \pm 0.81^{\mathrm{a}}$ & $5.45 \pm 0.93^{\mathrm{a}}$ & $5.43 \pm 0.71^{\mathrm{a}}$ \\
Taste & $5.33 \pm 1.21^{\mathrm{a}}$ & $5.45 \pm 1.18^{\mathrm{a}}$ & $5.23 \pm 1.31^{\mathrm{a}}$ \\
Aroma & $4.98 \pm 1.00^{\mathrm{a}}$ & $4.85 \pm 1.14^{\mathrm{a}}$ & $4.08 \pm 1.53^{\mathrm{b}}$ \\
Viscosity & $4.88 \pm 1.11^{\mathrm{b}}$ & $5.47 \pm 0.88^{\mathrm{a}}$ & $4.45 \pm 1.18^{\mathrm{b}}$ \\
Aftertaste & $5.15 \pm 1.08^{\mathrm{a}}$ & $5.16 \pm 0.92^{\mathrm{a}}$ & $5.05 \pm 1.04^{\mathrm{b}}$ \\
Overall Acceptability & $5.20 \pm 0.94^{\mathrm{b}}$ & $5.80 \pm 0.91^{\mathrm{a}}$ & $5.12 \pm 1.04^{\mathrm{b}}$ \\
\hline Mean values with different alphabets within the same row indicate significant difference $(\mathrm{p}<0.05)$
\end{tabular}

These sensory results also are supported by the physicochemical properties of samples with total soluble solids and total acidity of sauce samples which are presented in figure 1 and figure 2, respectively. All the formulations did not show a significant difference ( $p>0.05$ ) on total soluble solids and total acidity. However, there was slightly increased in total soluble solids with increasing in seaweed powder percentage as seaweed content of carrageenan which is soluble in water [17]. On the other hand, total acidity decreased slightly as seaweed powder can be functioned as alkalizing seasonings which neutralized the acids presented in the sauce samples [18]. 


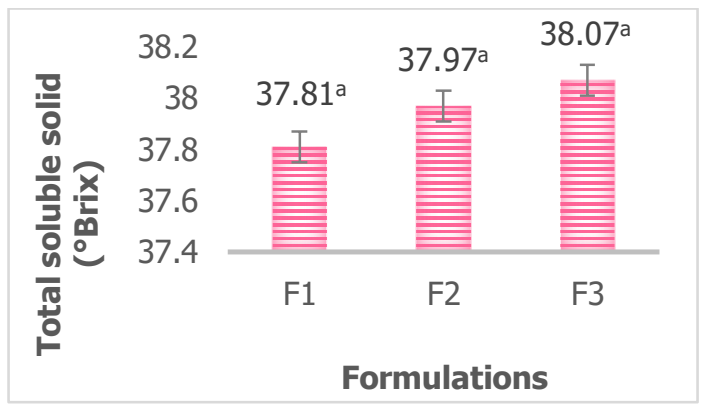

Figure 1: Total soluble solid of F1, F2 and F3.

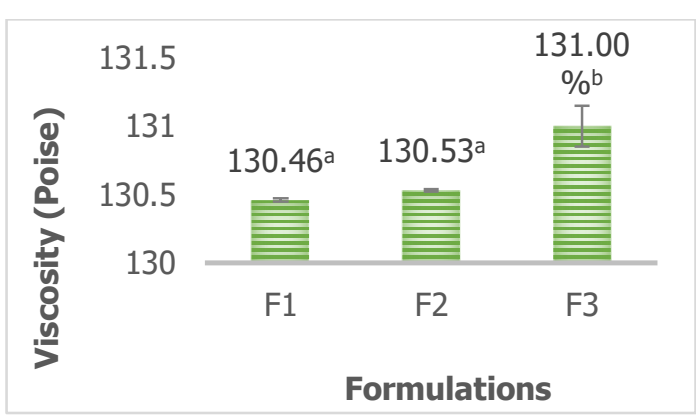

Figure 3: Viscosity of F1, F2 and F3.

F2 obtained the highest mean score in terms of viscosity (5.47) and aftertaste (5.60) which give the significant difference $(p<0.05)$ compared to other samples. The increasing composition of seaweed powder caused the viscosity of samples increased with a significant difference $(p<0.05)$ presented at the level of $3.0 \%$ as shown in figure 3 . The range of viscosity was $130.46-131.00$ poise. This is due to the increase in the amount of hydrocolloid, especially kappa-carrageenan, which can be dispersed in water and restrict the movement of molecules to form a bounded network in sauce [19]. The result of viscosity indicated that F3 with $3.0 \%$ seaweed powder had the lowest acceptability (4.45) among panellist due to its highest viscosity (131.00 poise) and gave the thickest body. In addition, the panellists were able to detect the fishy aftertaste when seaweed powder is used at the level of $3.0 \%$.

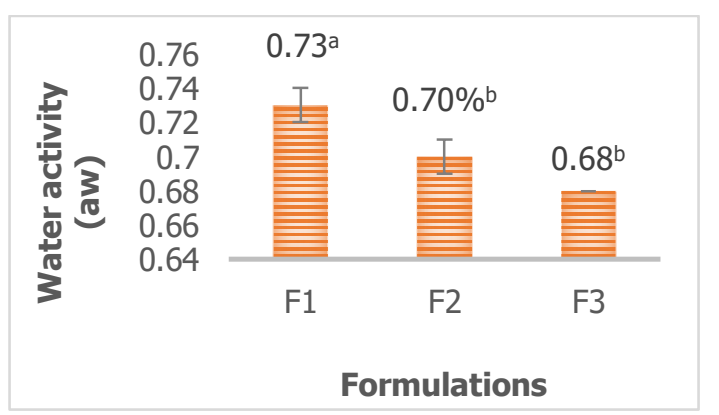

Figure 5: Water activity of F1, F2 and F3.

Besides that, figure 5 showed that increases in seaweed powder composition caused decreasing in water activity of

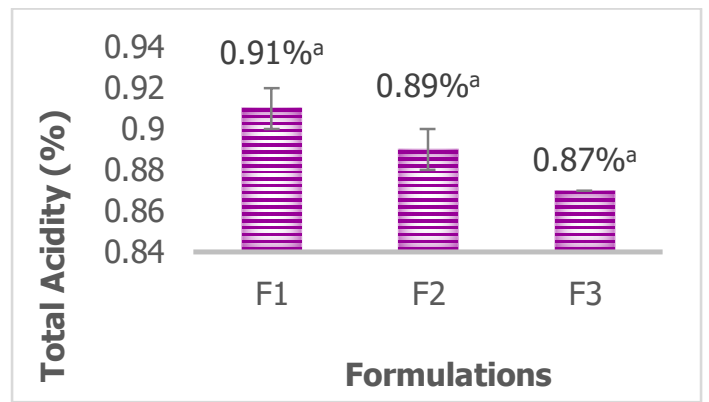

Figure 2: Total acidity of F1, F2 and F3.

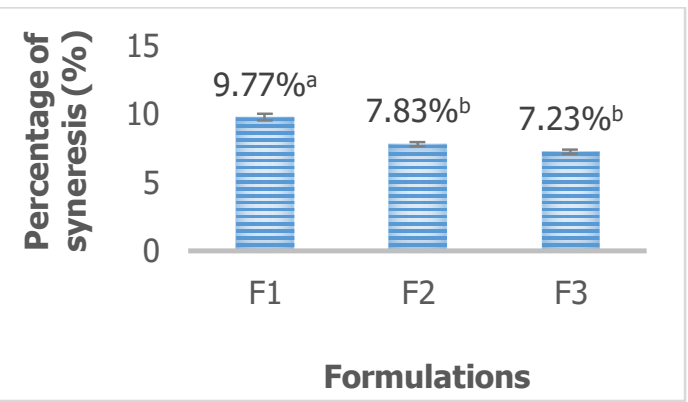

Figure 4: Percentage of syneresis of F1, F2 and F3.

For syneresis property, increasing the percentage of seaweed powder in the formulation caused by decreasing the percentage of syneresis. The syneresis ranges were $7.23 \%$ to $9.77 \%$ as shown in figure 4 . There was a significant difference $(\mathrm{p}<0.05)$ presented at a level of $2.5 \%$ seaweed powder (F2). Reported by [20] that Kappaphycus alvarezii which contains kappa-carrageenan as a major hydrocolloid can form a rigid or brittle gel in a liquid or semi-liquid structure which is characterized by high syneresis. Decreasing in syneresis due to the increase in the number of hydrocolloids presented in the sauce when increasing in seaweed powder composition. Thus increasing the gel strength as the resulted gel is more dense and compact so it has a good ability to form a more rigid network and to withstand weight per width area [21]. Thus, it can be assumed that $2.5 \%$ of seaweed powder can improve the quality of sauce by reducing the syneresis significantly $(\mathrm{p}<0.05)$.

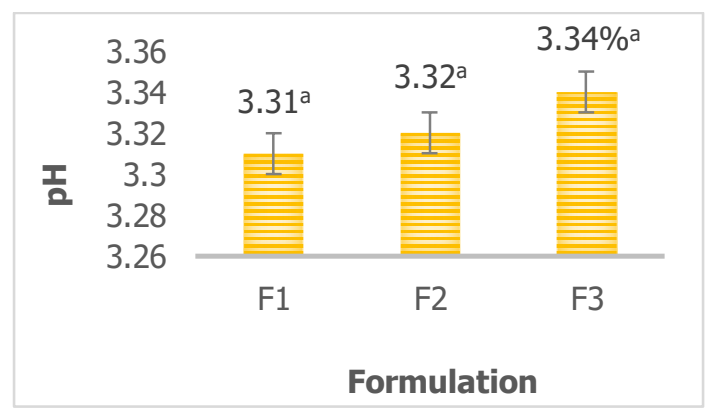

Figure 6: $\mathrm{pH}$ of F1, F2 and F3.

the sauce samples with a significant difference $(\mathrm{p}<0.05)$ presented in the level of $2.5 \%$ seaweed powder. [22] 
reported that water holding capacity was increased with the increasing of seaweed powder composition increasing, thus the powder can attract and hold more water in the food system, more bond water are formed and decreased the water activity as well as make the product more stable. On the other hand, figure 6 showed that increases in the composition of seaweed powder without affected too much on the $\mathrm{pH}$ of the sauce as the powder has an almost neutral $\mathrm{pH}$ value [23]. The result of $\mathrm{pH}$ showed no significant differences $(p>0.05)$ between all the formulations. Base on the sensory evaluation and physicochemical analysis, the best formulations (F2) has been chosen and was undergoing proximate analysis with the control.

\subsection{Nutrient Composition of the Control and the Best Pineapple-Chili Sauce Mixed with Seaweed (Kappaphycus alvarezii)}

There were significant difference $(p>0.05)$ found for moisture and crude fat content for the control and F2. The moisture content of the control and F2 were high, which were $71.99 \%$ and $72.54 \%$, respectively as presented in Table 2. Adding seaweed powder increased the moisture content of the sample due to the nature of it which has significant water holding capacity, which is $17.73 \mathrm{~g} / \mathrm{g}$ [24].

Table 2: Proximate values of control and best formulation (F2) samples.

\begin{tabular}{ccc}
\hline Nutrient Composition (\%) & Control & F2 \\
\hline Moisture & $71.99 \pm 0.07^{\mathrm{a}}$ & $72.54 \pm 0.37^{\mathrm{a}}$ \\
Ash & $1.50 \pm 0.15^{\mathrm{b}}$ & $2.70 \pm 0.03^{\mathrm{a}}$ \\
Crude protein & $0.29 \pm 0.0^{\mathrm{b}}$ & $0.37 \pm 0.01^{\mathrm{a}}$ \\
Crude fat & $0.18 \pm 0.06^{\mathrm{a}}$ & $0.14 \pm 0.02^{\mathrm{a}}$ \\
Crude fibre & $0.67 \pm 0.04^{\mathrm{b}}$ & $0.81 \pm 0.05^{\mathrm{a}}$ \\
Carbohydrate & $25.37 \pm 0.05^{\mathrm{a}}$ & $23.44 \pm 0.33^{\mathrm{b}}$ \\
\hline
\end{tabular}

Mean values with different alphabets within the same row indicate significant difference $(\mathrm{p}<0.05)$.

Ash content in F2 $(2.70 \%)$ was higher than the control samples $(1.50 \%)$ with a significant difference $(\mathrm{p}<0.05)$. This is because seaweed is rich in minerals such as sodium, potassium, calcium, magnesium, iron and phosphorus. Generally, the mineral content of seaweed was $8 \%$ to $40 \%$ [25]. According to [24], seaweed (Kappaphycus alvarezii) powder has relatively high ash content, which is $14: 52 \%$. In contrast, for the control sample, modified corn starch and xanthan gum used are artificial materials which lack minerals.

Moreover, the crude protein content in the control samples $(0.29 \%)$ and $\mathrm{F} 2(0.37 \%)$ were a significant difference $(\mathrm{p}<0.05)$. This is due to the use of different thickening agents in the two formulations. In a control sample, xanthan gum did not contain protein while modified corn starch only contained $0.26 \%$ protein. Thus, crude protein content was increased with the using of seaweed powder as a thickening agent as it contained $11.5 \%$ protein [24]. In addition, the crude fibre content of F2 $(0.81 \%)$ also significantly higher $(\mathrm{p}<0.05)$ compared to control $(0.67 \%)$. Finally, data obtained showed that the number of total carbohydrates significant reduction $(\mathrm{p}<0.05)$ in the total carbohydrates of F2 $(23.44 \%)$ compared to the control sample $(25.37 \%)$. Both formulations have low carbohydrate content since most of the nutritional composition made up of water. The use of seaweed powder which has a strong water holding capacity caused F2 to have a higher moisture content. In addition, F2 also has higher ash, crude fibre and crude protein content than that of the control formulation. Thus, seaweed (Kappaphycus alvarezii) powder has the potential to reduce the number of total carbohydrates in the sauce sample.

\section{CONCLUSION}

In overall, seaweed powder has influenced differently the quality of pineapple-chili sauce in terms of sensory evaluation, physicochemical properties and nutrition composition. Increasing in seaweed powder concentration did not change significantly the taste and colour of the sauce but it affected significantly the aroma and viscosity of the sauce. Increasing in seaweed powder concentration also improved the quality of sauce by reducing syneresis and water activity; however, a higher concentration of seaweed powder $(3.0 \%)$ make the sauce became more viscous and unacceptable. Pineapple-chili sauce mixed with seaweed produced from $2.5 \%$ seaweed powder was chosen the best formulation with significantly increased the percentage of crude fibre, protein and ash content.

\section{REFERENCES}

[1] Euromonitor International. Sauces, Dressings and Condiments in Malaysia, Euromonitor International Ltd, London, 2015

[2] Australian Food and Grocery Council. AFGF Market Insights: Malaysia, AFGC, Australia, 2014

[3] Simmonds, M., Preedy. VR, Nutritional Composition of Fruit Cultivars, Academic Press, Cambridge, 2015

[4] Peterson, J. Classical and Temporary Sauce Making, $2^{\text {nd }}$ end,: John Wiley \& Sons, Inc, New York, 2000. 
[15] AOAC. Association of Official Analytica Chemists, Washington DC, 2000.

[16] Mouritsen, OG. Seaweeds: Edible, Available, and Sustainable, University of Chicago Press, Chicago, 2013.

[17] Lersch, M.. Texture: A Hydrocolloid Recipe Collection, Creative Commons, California, 2008.

[18] Aniys A. http://www.naturallifeenergy.com/alkaline-vsacidic-foods/. 2018.

[19] Saha, D., Bhattacharya, S. Journal of Food Science and Technology, 47(6): 587-597, 2010

[9] Rahim, FA., Wash, H., Zakaria, MR., Ariff A, Kapri R, Ramli, N,. Ling, LS. Food Hydrocolloid 2014, 1-7. 2014.

[10] Farah, DA., Abdullah, A., Shahrul HZA., Chan, KM. International Food Research Journal, 22(5), 1977-1984, 2015.

[11] Masturah, EH., Maaruf, AG., Norlida, MD., Norhasidah, S. Australian Journal of Basic and Applied Sciences, 9(23), 528-532, 2015.

[12] Malaysia Pineapple Industry Board. http://www.mpib.gov.my/en/web/guest/sosnanas-bercili. 2018.

[13] Goan, EC. Quality of Applesauce and Raspberry Puree Applesauce as Affected by Type of Ascorbic Acid, Calcium Salts and Chelators under Stress Storage Conditions, University of Tennessee, Knoxville, 2011.

[14] Famurewa, JAV, Ibidapo, PO., Olaifa, Y. International Journal of Applied Science and Technology, 3(6), 34-42, 201.3
[20] Savary, G., Moreau, C., Cayot, N. Food Research International 43, 364-368, 2010.

[21] Kaya, AOW., Suryanib, A,, Santosoc. J, Ruslid, MS.. International Journal of Sciences: Basic and Applied Research 20(1), 313-324, 2015.

[22] Amanda YL, Mulya WK., Joko S. International Symposium on Aquatic Product Processing 1, 1-5, 2015.

[23] Ghani, MA http://www.ukmtech.com/v2/documents/produ cts/C-Weed_SUMMARY_V2.pdf., 2016.

[24] Sjamsiah, RN., Daik, R., Yarmo, MA., Ajdari, Z. Journal of Applied Phycology 26(2): 1049105, 2014.

[25] Abirami R., Kowsalya S. Journal of Agricultural Science and Technology 5(1), 1939-1250(2011). 